\title{
СПОРТИВНОЕ СООРУЖЕНИЕ КАК ФАКТОР УСПЕШНОГО РАЗВИТИЯ РЕГИОНОВ РОСИИИ
}

\section{Митяшин Г.Ю.}

Спортивное сооружение в современных условиях является неотьемлемой частью городской и региональной инфраструктуры. В работе представлен обзор подходов к оченке эффективности спортивного сооружения как инструмента повышения качества жизни населения, а также механизмы, позволяющие повысить эффективность его деятельности. Автором представлена информация об интегральном показателе уровня жизни и об индексе качества городской среды, при расчете которых необходимо использовать информацию о спортивных сооружениях. В работе произведен сравнительный анализ спортивных реестров разных стран, которые обеспечивают доступность информации о спортивной инфраструктуре для населения, выявлены критерии, необходимые для совершенствования российского реестра. Также, на основе анализа данных конкурса “Арена” были сформулированы более эффективные критерии оченки деятельности спортивного сооружения.

Цель исследования: выполнить обзор подходов коченке эффективности спортивного сооружения как инструмента повышения качества жизни населения.

Метод или методология проведения работы: метод анализа и синтеза, метод описания.

Результаты: выявлены инструменты повышения эффективности спортивного сооружения, как фактора, влияющего на уровень жизни региона.

Область применения результатов: полученные результать иелесообразно применять Министерству спорта РФ при разработке требований к спортивным объектам; работникам служб, 
занимаюшихся территориальным планированием; органам управления при разработке мероприятий по повышению уровня жизни.

Ключевые слова: спортивное сооружение; уровень жизни; региональное развитие.

\section{SPORTS FACILITIES AS A FACTOR OF SUCCESSFUL DEVELOPMENT OF RUSSIAN REGIONS}

\section{Mityashin G.Yu.}

Sports facilities are essential part of city and municipal infrastructure nowadays. This article presents an overview of approaches to evaluating the effectiveness of sports facilities as a tool for improving the quality of people's life. Moreover, this paper presents mechanisms that can improve the effectiveness of a sports facility. The author provides information about the integral indicator of living standard and about urban environment quality index, which are calculated using information about sports facilities. The paper provides a comparative analysis of sports registries of different countries, which provide access to information about sports infrastructure for the population; the criteria necessary for improving the Russian registry are identified. Also, based on the analysis of data from the "Arena" competition, more effective criteria for evaluating the performance of sports facilities were formulated.

Purpose: perform a review of approaches to evaluating the effectiveness of sports facilities as a tool for improving the quality of people's life.

Methodology: in this article method of analysis and synthesis, methods of description were used.

Results: tools for improving the effectiveness of sports facilities as a factor affecting the standard of living of the region were identified.

Practical implications: the results should be used by the Ministry of sport of the Russian Federation for developing requirements for sports facilities; employees of territorial planning services; services which develop measures to improve living standards.

Keywords: sports facilities; standard of living; regional development. 


\section{Введение}

\section{Тенденции развития спортивной инфраструктуры в РФ}

В наши дни в Российской Федерации уделяется особое внимание вопросам развития спорта и спортивной инфраструктуры. Государство активно разрабатывает комплекс мероприятий по привлечению населения к здоровому образу жизни, а также принимает меры по созданию условий для включения России в глобальную спортивную индустрию. Целями правительства РФ при реализации данных программы являются:

- увеличение процент населения, занимающегося спортом до 55\%;

- увеличение показателя здоровой жизни граждан до 67 лет [16].

За последние 10 лет были предложены, одобрены и реализованы программы, направленные на развитие спорта и физической культуры в регионах России. Самыми масштабными и значимыми среди них были:

- федеральная целевая программа «Развитие физической культуры и спорта в Российской Федерации»;

- региональные программы «Развитие физической культуры и спорта»;

- применение механизмов ГЧП (государственно-частного партнерства) для реализации инфраструктурных проектов в области физической культуры и спорта [17].

Данные программы решают следующие задачи:

- создание необходимых условий, обеспечивающих гражданам возможность регулярно заниматься сортом и физической культурой;

- повышение уровня подготовки спортсменов в спорте высших достижений;

- развитие инфраструктуры физической культуры и спорта, в том числе в рамках государственно-частного партнерства;

- реконструкция объектов, расположенных в шаговой доступности, с созданием комфортных условий для лиц с ограниченными возможностями;

- совершенствование материально-технической базы для подготовки спортсменов высшего спорта и тренеров с учетом природно-климатических особенностей регионов России; 
- создание необходимых условий для подготовки и сохранения спортивного резерва;

- усиленное развитие спортивной инфраструктуры в СевероКавказском федеральном округе, Республике Крым и г. Севастополе, Калининградской области и Арктической зоне [18].

За последние 10 лет на территории Российской Федерации прошло множество крупных спортивных соревнований, самыми значимыми из которых являются:

1. XXII Олимпийские зимние игры и XI Параолимпийские зимние игры2014 в г. Сочи;

2. XXVII Всемирная летняя Универсиада 2013 в г. Казань;

3. XXIX Всемирная зимняя Универсиада 2019 в г. Красноярск;

4. Чемпионат мира по футболу 2018 [12].

Как для вовлечения населения в занятия спортом, так и для проведения крупных спортивных мероприятий необходима развитая спортивная инфраструктура $[8,9,20]$ - как материальная (спортивные сооружения), так и организационная (спортивные школы, клубы и т. д.) [12].

На начало 2010 года в России насчитывалось 243141 спортивных сооружений, на конец 2019 года их количество возросло до 311905. Таким образом, повышенное внимание к проблемам развития спорта и физической культуры в РФ привело к постройке 68764 новых спортивных объектов [17].

При этом важно понимать, что развитие спорта и строительство спортивной инфраструктуры самоцелью не является. Оно служит лишь инструментом для повышения качества жизни населения [21]. Кроме того, такие значительные инвестиционные проекты могут способствовать экономическому росту тех регионов, где они осуществляются.

Это позволяет поставить вопрос о том, какова эффективность строительства спортивных сооружений с точки зрения их роли в развитии российских регионов [4].

Вопросами оценки эффективности в сфере спорта занимался ряд специалистов $[3,6,15]$. Проблемам управления и строительства спортивных сооружений посвящено достаточно много работ. В них было 
рассмотрено влияние спортивного объекта мирового уровня на имидж региона [8], а также проблемы строительства спортивной инфраструктуры. Они рассматривались в двух аспектах: необходимость проведения спортивных соревнований и выбор оптимального механизма развития инфраструктуры (а также риски, связанные с неэффективностью этого механизма [11]). Таким механизмом стало государственно-частное партнерство (ГЧП) [7, 13, 19]. Однако исследователи не рассматривали влияние уже построенного спортивного сооружения на развитие региона, на территории которого оно построено.

Цель исследования - выполнить обзор подходов к оценке эффективности спортивного сооружения как инструмента повышения качества жизни населения.

\section{Результаты и обсуждение}

\section{Спортивное сооружение как фактор,} влияющий на уровень жсизни

В таблице 1 представлены данные об уровне жизни и обеспеченности спортивными сооружениями России, Германии и Финляндии. На основе таблицы видно, что количество спортивных сооружений на 100000 человек в России составляет 213 штук, в то время как в Финляндии этот показатель достигает 652, а итоговый ВВП России практически идентичен ВВП Германии. Сравнивая обеспеченность населения спортивными сооружениями и ВВП (по паритету покупательской способности) на душу населения можно сделать вывод, что на данный момент бюджет, выделяемый на развитие и поддержание спортивной инфраструктуры в России, не является достаточным [18].

В таблице 2, составленной на основании данных об интегральном показателе, представлено соотношение между ИП (интегральным показателем) уровня жизни и количеством спортивных объектов на территории каждого региона [10]. Интегральный показатель уровня жизни - характеристическая оценка качества жизни на территории субъекта Российской Федерации, составленная на основе анализа 72 показателей. 
Таблицуа 1.

Уровень жизни в Германии, Финляндии и России

\begin{tabular}{|c|c|c|c|c|}
\hline Показатели & & Германия & Финляндия & Россия \\
\hline $\begin{array}{l}\text { Численность населе- } \\
\text { ния / чел. }\end{array}$ & & 83019200 & 5519586 & 146510064 \\
\hline $\begin{array}{l}\text { Количество спортив- } \\
\text { ных сооружений }\end{array}$ & & 231441 & 36000 & 311905 \\
\hline $\begin{array}{l}\text { Количество спортив- } \\
\text { ных сооружений на } \\
100000 \text { человек }\end{array}$ & & 279 & 652 & 213 \\
\hline \multirow{2}{*}{$\begin{array}{l}\text { ВВП (по паритету } \\
\text { покупательской спо- } \\
\text { собности) }\end{array}$} & итоговый & 4,356 трлн.дол. & 256 млрд.дол. & 4,213 трлн.дол \\
\hline & $\begin{array}{c}\text { на душу } \\
\text { населения }\end{array}$ & 52470 дол & 46380 дол. & 28755 дол. \\
\hline $\begin{array}{l}\text { Средняя заработная } \\
\text { плата / мес. }\end{array}$ & $\begin{array}{c}\text { на душу } \\
\text { населения }\end{array}$ & $\begin{array}{c}3979,22 \text { евро } \\
(283619 \text { руб.) }\end{array}$ & $\begin{array}{l}3560,59 \text { евро } \\
(253781 \text { руб.) }\end{array}$ & 46509 руб. \\
\hline $\begin{array}{l}\text { Прожиточный мини- } \\
\text { мум / мес. }\end{array}$ & $\begin{array}{c}\text { на душу } \\
\text { населения }\end{array}$ & $\begin{array}{c}1240 \text { евро } \\
\text { (88 381руб.) }\end{array}$ & $\begin{array}{c}1170 \text { евро } \\
\text { (83 } 392 \text { руб.) }\end{array}$ & 11185 руб. \\
\hline $\begin{array}{l}\text { Минимальная зара- } \\
\text { ботная плата / мес. }\end{array}$ & $\begin{array}{c}\text { на душу } \\
\text { населения }\end{array}$ & $\begin{array}{c}1526 \text { евро } \\
\text { (108757руб.) }\end{array}$ & $\begin{array}{c}1700 \text { евро } \\
\text { (121 } 167 \text { руб.) }\end{array}$ & 11185 руб. \\
\hline
\end{tabular}

Курс евро на момент исследования 72.18руб.

Данные показатели объединены в 11 групп, характеризующих ключевые аспекты качества жизни в регионе: уровень доходов населения; занятость населения и рынок труда; жилищные условия населения; безопасность проживания; демографическая ситуация; экологические и климатические условия; здоровье населения и уровень образования; обеспеченность объектами социальной инфраструктуры; уровень экономического развития; уровень развития малого бизнеса; освоенность территории и развитие транспортной инфраструктуры.

Таблица 2.

Интегральный показатель уровня жизни регионов России

\begin{tabular}{|c|c|c|c|c|}
\hline № & Субъект РФ & ИП & $\begin{array}{c}\text { Количество } \\
\text { спортивных объектов }\end{array}$ & $\begin{array}{c}\text { Количество } \\
\text { населения }\end{array}$ \\
\hline 1 & Москва & 77.37 & 21902 & 12506468 \\
\hline 2 & Санкт-Петербург & 75.69 & 7697 & 5351935 \\
\hline 3 & Московская область & 72.45 & 10721 & 7503385 \\
\hline 4 & Татарстан & 66.15 & 11013 & 3894284 \\
\hline
\end{tabular}


Окончание табл. 2.

\begin{tabular}{|c|c|c|c|c|}
\hline 5 & Белгородская область & 64.43 & 5892 & 1549876 \\
\hline 6 & Краснодарский край & 63.97 & 10396 & 5603420 \\
\hline 7 & Воронежская область & 60.76 & 6166 & 2333768 \\
\hline 8 & $\begin{array}{c}\text { Ханты-Мансийский } \\
\text { автономный округ }\end{array}$ & 60.11 & 3220 & 1655074 \\
\hline 9 & Липецкая область & 59.25 & 3522 & 1150201 \\
\hline 10 & $\begin{array}{c}\text { Калининградская } \\
\text { область }\end{array}$ & 58.94 & 2029 & 994599 \\
\hline
\end{tabular}

На основании данных, представленных в таблице 2, видно, что в регионах с более высоким населением больше спортивных сооружений. Однако, в наиболее населенных субъектах РФ (Москва, Московская область, Санкт-Петербург) на каждое спортивное сооружение приходится больше человек, что говорит о количественном недостатке спортивной инфраструктуры. В менее населённых регионах России население лучше обеспечено спортивными сооружениями $[2,12]$.

Следующей важной характеристикой уровня жизни является индекс качества городской среды. Данный параметр рассчитывается в соответствии с Распоряжением Правительства РФ от 23 марта 2019 г. № 510-р “Об утверждении Методики формирования индекса качества городской среды”. Для анализа комфорта проживания в регионе используется 36 показателей, в числе которых:

- разнообразие культурно-досуговой и спортивной инфраструктуры;

- доступность спортивной инфраструктуры.

Индикатор разнообразия культурно-досуговой спортивной инфраструктуры рассчитывается при помощи коэффициента вариации (разнообразия) по количеству культурных и спортивных учреждений в городе. Чем больше в городе разных видов культурно-спортивных учреждений, тем больше коэффициент и, соответственно, выше показатель.

Индикатор доступности спортивной инфраструктуры рассчитывается следующим образом: первые 50 процентов оценки по индикатору вычисляются как доля населения, проживающего в радиусе 
800 метров от спортивных площадок, в общей численности населения, вторые 50 процентов оценки по индикатору вычисляются как отношение количества спортивных сооружений к численности населения города [3].

Включение данных индикаторов в систему формирования оценки качества городской среды указывает на необходимость совершенствования спортивной инфраструктуры в городах России наравне с уровнем освещенности улиц и уровнем озеленения.

\section{Оценка доступности информации об объектах спорта}

На территории Российской Федерации на данный момент действует приказ Министерства спорта о внесении изменений в Методические рекомендации о применении нормативов и норм при определении потребности субъектов Российской Федерации в объектах физической культуры и спорта, утвержденные приказом Министерства спорта Российской Федерации от 21 марта 2018 г. N 244 «Об утверждении Методических рекомендаций о применении нормативов и норм при определении потребности субъектов Российской Федерации в объектах физической культуры и спорта». В данном приказе приводится информация о том, что первоочередной задачей развития спортивной инфраструктуры к 2030 году является обеспечение и привлечение к систематическим занятиям физической культурой не менее 3 часов в неделю всех трудоспособных граждан в возрасте до 79 лет и детей возрастом от 3 лет. Критерием позволяющим определить готовность спортивных сооружений принимать необходимое количество человек является единовременная пропускная способность (ЕПС). Нормальное значение данного критерия (ЕПС составляет 122 человека в городах федерального подчинения и 72 в прочих субъектах РФ.

Однако, показатель ЕПС позволяет оценить лишь количественную обеспеченность населения спортивными сооружениями. При этом никак не регламентированы специфичные потребности населения каждого региона. Так, например, в Республике Ингушетия центр единоборств будет более востребован, чем футбольный ста- 
дион, а в Красноярском крае ледовая арена будет более актуальна, нежели плавательный бассейн. Более того на данный момент в России не существует такой базы, где были бы представлены все спортивные сооружения и услуги которые они предоставляют. Функционирующей на данный момент спортивный реестр не содержит в себе необходимой информации об услугах и специфике каждого спортивного сооружения. Он отражает лишь такую информацию как адрес, индекс, базовую характеристику (ледовая арена, крытый стадион).

Реестры стран Европы являются более проработанными и удобными в использовании. Например, Lipas - национальная база данных спортивных сооружений Финляндии включает максимально полные данные по различным объектам, показывает объекты на карте, описывает типологию и дает ссылки на сайты объектов. Один и тот же объект может быть записан в две или даже три разные категории, отражающие разные сезонные использования (например, лето/зима). Или Sports Facility Register - норвежский реестр спортивных объектов созданный в 1992 году является эталонным. Он содержит следующие сведения о каждом спортивном сооружении:

- Год строительства ;

- Местонахождение;

- Статус (может быть действующим, не действующим, временно закрытым, закрытым, проектом, удаленным, или нереализованным);

- Класс объекта (уездный объект, межмуниципальный объект, муниципальный объект, национальная арена, местный объект или национальный объект);

- Группа объектов (может быть 25 различных категорий, например, футбольный центр, объект для автоспорта и т.д.);

- Подгруппа объекта (группа с подгруппами, например, футбольные центры можно разделить по типам: трава, гравий, искусственное покрытие, мини-зал 40 х 20 м, большой зал 100 x 60 м, тренажерный зал 70 х 50 м или неопределенный). 


\section{Оценка эффективности деятельности объектов спорта}

Помимо доступной информации о спортивном сооружении также необходимо качественно оценивать эффективность его деятельности. Оценка эффективности деятельности спортивной инфраструктуры производится на основании фактической загруженности спортивного сооружения за период и нормативной мощности спортивного сооружения за период. То есть затраты на строительство и поддержание объекта в рабочем состоянии в Российской методике оценивания не влияют на его эффективность. Таким образом, предполагается, что поддерживать в рабочем состоянии небольшой физкультурно-оздоровительный комплекс так же дешево, как и стадион вместимостью 15000 человек.

В Норвегии применяется наиболее детальная система оценки эффективности спортивного объекта. Она производится с учетом следующих факторов:

- Стоимость строительства;

- Ежегодные эксплуатационные затраты;

- Количество объектов (если спортивный комплекс разбит на несколько частей ввиду их специфики);

- Площадь спортивной зоны объекта (объектов);

- Типология спортивного объекта;

- Местоположение объекта спорта (т.е. при оценке учитывается количество жителей региона, доходы 1 жителя и расходы на 1 жителя) [14].

С целью совершенствования методики оценивания спортивных сооружений и адаптации западного опыта в Российской Федерации был проведен II Национальный конкурс «АРЕНА» на образцовое спортивное сооружение. В данном конкурсе приняли участие 235 спортивных сооружений из 61 региона России. Для принятия участия в конкурсе спортивному объекту было предложено заполнить предлагаемую заявку, которая включает в себя все критерии оценки эффективности сооружения. Предоставленные данные были сгруппированы по 5 критериям [1].

1. Архитектура и внутренний дизайн (генеральный проектировщик, проводивший строительство/реконструкцию объекта; со- 
стояние фасадов сооружения; состояние внутренних помещений и оборудования).

2. Функциональность (поэтажные планы с экспликацией помещений; единовременная пропускная способность (ЕПС), количество зрительских мест; количество парковочных мест; возможность трансформации спортивных зон для использования под другие виды спорта или для проведения неспортивных мероприятий; возможность проведения телетрансляций; типы и количество зон питания; наличие кейтеринговых услуг; характеристики спортивных зон и вспомогательных помещений).

3. Эффективность деятельности (количество соревнований, проведенных на объекте за отчетный период; количество штатных сотрудников; выполнение работ по эксплуатации спортивного сооружения по договорам аутсорсинга; регламенты по эксплуатации спортивного сооружения; структура операционных доходов/расходов объекта; соотношение операционных доходов и расходов за последний отчетный период; перечень оказываемых услуг по абонементам; фактическая загруженность спортивного объекта; количество занимающихся на объекте (в год); информационная открытость объекта).

4. Соответствие требованиям технического регулирования (сертификация объекта, сертификация спортивного оборудования в системе ГОСТ, наличие Паспорта безопасности объекта, оснащение объекта системами цифрового мониторинга, охрана труда и защита окружающей среды, стандарты и нормативы при эксплуатации и управлении объектом).

5. Доступность для маломобильных групп населения (наличие паспорта доступности и акта обследования на предмет доступности объекта для МГН; наличие специального спортивно-технологического оборудования для параолимпийского спорта и адаптивной физической культуры; количество зрительских мест, наличие санузлов, оборудованных для МГН; количество проводимых мероприятий по параолимпийским видам спорта и адаптивной физической культуре в год, наиболее значимые мероприятия по параолимпийским видам спорта и адаптивной физической культуре). 
Данные, которые необходимо было заполнить в анкете, максимально полно отражают все аспекты деятельности спортивного сооружения. Они раскрывают экономическую составляющую деятельности объекта, оснащенность современными технологиями, функциональность, доступность для маломобильного населения и общий уровень состояния объекта.

На основании вышеизложенных данных и анализа конкурса "Арена" Российской ассоциацией спортивных сооружений была сформирована таблица 3 , которая показывает существующие сейчас и предлагаемые методики оценки эффективности деятельности спортивного сооружения. Данный конкурс проходил с 1 мая по 24 октября 2019 года. Его организаторами выступили Олимпийский и Паралимпийский комитеты Российской Федерации и Российская ассоциация спортивных сооружений. Второй национальный конкурс “Арена” приведен с целью содействия формированию общероссийских стандартов качества спортивных сооружений, улучшению качества работы спортивных сооружений и повышению эффективности их эксплуатации, созданию благоприятных условий для проведения спортивных мероприятий и оказания физкультурно-спортивных услуг населению.

Таблица 3 .

Текущие и предлагаемые критерии оценки эффективности спортивного сооружения (источник - внутренняя корпоративная документация)

\begin{tabular}{|l|l|}
\hline \multicolumn{1}{|c|}{ СУЩЕСТВУЮЩИЕ } & \multicolumn{1}{|c|}{ ПРЕДЛАГАЕМЫЕ } \\
\hline Оценка населения, регулярно занимающегося & Площадь спортивной зоны \\
физической культурой и спортом в области & объекта (для каждого вида \\
Количество недель физкультурно-спортивной & спорта) \\
активности регулярно занимающихся & Эксплуатационные затраты \\
Фактическая загруженность спортивных со- & Оснащенность современными \\
оружений & инженерными системами \\
Годовая мощность спортивных сооружений & Оборудование спортивное \\
Расчет фактической загруженности спортив- & (уровень, тип) \\
ных сооружений & Региональные особенно- \\
Мощность спортивного сооружения в зависи- & сти местоположения объекта \\
мости от типа & спорта \\
Расчет годовой мощности спортивных соору- & Типология спортивных объ- \\
жений & ектов \\
\hline
\end{tabular}


В таблице 3 в левом столбце изложены применяемые сейчас методы оценивания, а в правом столбце представлены инновационные методы, применение которых в совокупности с существующими позволит повысить эффективность использования объектов спорта. Совершенствование критериев оценки эффективности спортивного сооружения необходимо для повышения качества управления объектом, что в свою очередь приводит к повышению качества предоставляемых услуг.

\section{Вывод}

На данный момент государство уделяет достаточно большое влияние вопросам спорта и его популяризации в России. Об этом свидетельствует стратегические цели (увеличить процент населения, занимающегося спортом до 55\%, увеличить показатель здоровой жизни граждан до 67 лет) Министерства спора. Тем не менее, уделяется недостаточно внимания оценке эффективности спортивного объекта, что снижает скорость достижения стратегической цели. Таким образом изменение реестра спортивных объектов окажет благоприятное влияние на популяризацию спорта на территории Российской Федерации, так как граждане смогут получать всю необходимую информацию о спортивных сооружениях и быстро выбирать наиболее подходящее. С другой стороны, изменение методики оценки эффективности спортивных объектов позволит оптимизировать работу сооружений, что позволит им повысить качество и количество предоставляемых услуг, а учет региональной специфики обеспечит населению доступность наиболее востребованных видов спорта

Таким образом, грамотное управление спортивным объектом и информацией о нем позволит регионам России активнее популяризировать спорт и здоровый образ жизни, что, несомненно, благоприятно влияет на успешное развитие каждого региона и страны в целом, поскольку способствует повышению качества жизни населения и сохранению и накоплению человеческого капитала. 


\section{Список литературы}

1. Арена конкурс на образцовое спортивное сооружение [Электронный pecypc]. URL: http://arenakonkurs.ru/ (дата обращения: 08.03.2020).

2. Барбарук А. И., Красюк И. А. Маркетинговое исследование рынка фитнес-услуг в России и Санкт-Петербурге // Juvenis Scientia. 2018. № 11. С. 28-31.

3. Бахарев В.В. Обеспечение конкурентоспособности фитнес-центров // Экономика и менеджмент систем управления. 2014. № 1. С. 10-15.

4. Богатырева С.В., Титов А.Б., Куприянова М.Ю. Экономическая эффективность как основа формирования управленческих решений // Экономика и менеджмент систем управления. 2016. Т. 20. № 2.1. C. $116-122$.

5. Вертакова Ю.В., Клевцова М.Г., Плотников В.А. Оценка экономического влияния крупных спортивных проектов на имидж региона // Теория и практика физической культуры. 2017. № 6. С. 42-44.

6. Гермина Л.А., Гетман Е.П., Воеводина С.С. Управление деятельностью спортивной индустрии // Физическая культура, спорт - наука и практика. 2017. № 4. С. 58.

7. Григорьев В.И., Плотников В.А. Государственно-частное партнерство в развитии физической культуры и спорта // Теория и практика физической культуры. 2014. № 8. С. 102-104.

8. Засимова Л.С., Локтев Д.А. Занятия спортом - удел богатых? (Эмпирический анализ занятий спортом в России) // Экономический журнал Высшей школы экономики. 2016. Т. 20. № 3. С. 471-499.

9. Зюрин Э.А., Рослая В.С., Коляскина Т.Ю., Сяфуков М. Р. Физкультурно-спортивные клубы как механизм реализации социально значимых проектов подготовки населения к выполнению испытаний (тестов) комплекса ГТО // Вестник спортивной науки. 2017. № 2. С. 47-52.

10.Интегральный показатель уровня жизни в регионах // russia.duck. consulting [Электронный pecypc]. URL: https://russia.duck.consulting/ maps/12/2018 (дата обращения: 07.03.2020).

11. Капогузов Е. А. Уроки «Мостовика»: строительство спортивной инфраструктуры и политико-административный ресурс // ЭКО. 2018. № 7. C. 131-145. 
12.Крупнейшие спортивные соревнования в РФ // ru.wikipedia. org [Электронный pecypc]. URL: https://ru.wikipedia.org/wiki/ Категория:Спортивные_соревнования_в_России (дата обращения 07.03.2020).

13. Крылова Е.М., Абрамкина Н.П. Институт государственно-частного партнерства как инструмент развития сферы физической культуры и спорта // Экономика и предпринимательство. 2017. № 2-2. С. 350-353.

14.Норвежский реестр спортивных сооружений// anlegg.skiskyting.no/ [Электронный pecypc]. URL: https://anlegg.skiskyting.no/ (дата обращения: 07.03.2020).

15. Седнев А.В. Управление спортивным объектами // Спортивный менеджмент: актуальные проблемы, практический опыт и перспективы. Сборник научных статей. Нижний Новгород: ННГУ им. Н.И. Лобачевского, 2020. С. 131-135.

16. Стратегия развития объектов спорта до 2035. //static.government. ru [Электронный ресурс]. URL: http://static.government.ru/media/ files/hAdS1Ag79t4b0gc0fxhmA6MZb8VLbYGR.pdf (дата обращения: 07.03.2020).

17. Федеральные программы развития спорта // www.minsport.gov.ru [Электронный ресурc]. URL: https:/www.minsport.gov.ru/activities/ federal-programs/ (дата обращения 07.03.2020).

18. ФЦП развитие физкультуры и спорта //docs.cntd.ru [Электронный pecypc]. URL: http://docs.cntd.ru/document/420248844 (дата обращения 07.03.2020).

19. Цепелева А.Д. Реализация государственно-частного партнерства для развития сферы массового спорта // Известия Санкт-Петербургского государственного экономического университета. 2015. № 3. С. 149 153.

20.Шинкевич А.И., Ногуманов Р.У. Экономическое содержание инфраструктуры сферы спортивных услуг // Российское предпринимательство. 2017. Т. 18. № 8. С. 1413-1420.

21. Mamcarczyk M., Poplawski L. Access to Sport Facilities, Social and Intergenerational Integration: A Case Study // European Research Studies Journal. 2020. V. 23. No 2, pp. 577-591. 


\section{References}

1. Arena konkurs na obraztsovoe sportivnoe sooruzhenie [arena competition for an exemplary sports facility]. http://arenakonkurs.ru/

2. Barbaruk A.I., Krasyuk I.A. Marketingovoe issledovanie rynka fitnesuslug v Rossii i Sankt-Peterburge [Marketing research of the market of fitness services in Russia and St. Petersburg]. Juvenis Scientia. 2018. No. 11, pp. 28-31.

3. Bakharev V.V. Obespechenie konkurentosposobnosti fitnes-tsentrov [Ensuring the competitiveness of fitness centers]. Economics and management control systems. 2014. No. 1, pp. 10-15.

4. Bogatyreva S.V., Titov A.B., Kupriyanova M.Yu. Ekonomicheskaya effektivnost' kak osnova formirovaniya upravlencheskikh resheniy [Economic efficiency as the basis for the formation of management decisions]. Economics and Management Systems Management. 2016. T. 20. No. 2.1, pp. 116-122.

5. Vertakova Yu.V., Klevtsova M.G., Plotnikov V.A. Otsenka ekonomicheskogo vliyaniya krupnykh sportivnykh proektov na imidzh regiona [Evaluation of the economic impact of major sports projects on the image of the region]. Theory and Practice of Physical Culture. 2017. No. 6, pp. 42-44.

6. Germina L.A., Getman E.P., Voevodina S.S. Upravlenie deyatel'nost'yu sportivnoy industrii [Management of the sports industry]. Physical Culture, Sport - Science and Practice. 2017. No. 4. P. 58.

7. Grigor'ev V.I., Plotnikov V.A. Gosudarstvenno-chastnoe partnerstvo v razvitii fizicheskoy kul'tury i sporta [Public-private partnership in the development of physical education and sports]. Theory and practice of physical education. 2014. No. 8, pp. 102-104.

8. Zasimova L.S., Loktev D.A. Zanyatiya sportom - udel bogatykh? (Empiricheskiy analiz zanyatiy sportom $v$ Rossii) [Sports - the lot of the rich? (An empirical analysis of sports in Russia)]. Economic Journal of the Higher School of Economics. 2016. V. 20. No. 3, pp. 471-499.

9. Zyurin E.A., Roslaya V.S., Kolyaskina T.Yu., Syafukov M.R. Fizkul'turno-sportivnye kluby kak mekhanizm realizatsii sotsial'no znachimykh proektov podgotovki naseleniya $\mathrm{k}$ vypolneniyu ispytaniy (testov) kom- 
pleksa GTO [Sports clubs as a mechanism for the implementation of socially significant projects to prepare the population to perform tests of the GTO complex]. Vestnik sports science. 2017. No. 2, pp. 47-52.

10. https://russia.duck.consulting/maps/12/2018

11. Kapoguzov E.A. Uroki «Mostovika»: stroitel'stvo sportivnoy infrastruktury i politiko-administrativnyy resurs [Lessons "Mostovika": the construction of sports infrastructure and political and administrative resource]. ECO. 2018. No. 7, pp. 131-145.

12. Krupneyshie sportivnye sorevnovaniya $v R F$ [The largest sports facilities in Russia]. https://ru.wikipedia.org/wiki/Kategoriya:Sportivnye_sorevnovaniya_v_Rossii

13. Krylova E.M., Abramkina N.P. Institut gosudarstvenno-chastnogo partnerstva kak instrument razvitiya sfery fizicheskoy kul'tury i sporta [The Institute of Public-Private Partnership as a Tool for the Development of the Field of Physical Culture and Sports]. Economics and Entrepreneurship. 2017. No. 2-2, pp. 350-353.

14. Norvezhskiy reestr sportivnykh sooruzheniy [Norwegian Register of Sports Facilities]. https://anlegg.skiskyting.no/

15. Sednev A. V. Upravlenie sportivnym obektami [Management of sports facilities]. Sportivnyy menedzhment: aktual'nye problemy, prakticheskiy opyt i perspektivy. Sbornik nauchnykh statey [Sports management: actual problems, practical experience and prospects. Collection of scientific articles]. Nizhny Novgorod: UNN them. N.I. Lobachevsky, 2020, pp. 131-135.

16. Strategiya razvitiya ob" ektov sporta do 2035 [Strategy for the development of sports facilities until 2035]. http://static.government.ru/media/ files/hAdS1Ag79t4b0gc0fxhmA6MZb8VLbYGR.pdf

17. Federal'nye programmy razvitiya sporta [Federal Sports Development Programs]. https://www.minsport.gov.ru/activities/federal-programs/

18. FTs P razvitie fizkul 'tury i sporta [Federal target program for the development of physical education and sports]. http://docs.cntd.ru/document/420248844

19. Tsepeleva A. D. Realizatsiya gosudarstvenno-chastnogo partnerstva dlya razvitiya sfery massovogo sporta [Implementation of public-private part- 
nerships for the development of the field of mass sports]. Journal of St. Petersburg State University of Economics. 2015. No. 3, pp. 149-153.

20. Shinkevich A.I., Nogumanov R.U. Ekonomicheskoe soderzhanie infrastruktury sfery sportivnykh uslug [The economic content of the infrastructure of sports services]. Russian Journal of Entrepreneurship. 2017. V. 18. No. 8, pp. 1413-1420.

21. Mamcarczyk M., Poplawski L. Access to Sport Facilities, Social and Intergenerational Integration: A Case Study. European Research Studies Journal. 2020. V. 23. No 2, pp. 577-591.

\section{ДАННЫЕ ОБ АВТОРЕ}

Митяшин Глеб Юрьевич, бакалавр направления “Торговое дело" Федеральное государственное автономное образовательное учреждение высшего образования «Санкт-Петербургский политехнический университет Петра Великого» ул. Политехническая, 29, г. Санкт-Петербург, 194064, Российская Федерация gleb.mityashin@yandex.ru

\section{DATA ABOUT THE AUTHOR}

Mityashin Gleb Yurievich, Bachelor of "Trade"

Peter the Great St. Petersburg Polytechnic University 29, Politekhnicheskaya Str., St. Petersburg, 194064, Russian Federation gleb.mityashin@yandex.ru 